\title{
SUSCETIBILIDADE DE GOTEJADORES AO ENTUPIMENTO DE CAUSA BIOLÓGICA ${ }^{1}$
}

\author{
Ronaldo Souza Resende ${ }^{2}$, Rubens Duarte Coelho ${ }^{3}$ \& Sônia Maria de Stéfano Piedade ${ }^{4}$
}

\begin{abstract}
RESUMO
Avaliou-se a suscetibilidade de cinco tipos de gotejadores ao processo de entupimento de origem biológica, testando-se os seguintes modelos da marca comercial Netafim: Streamline 100, Ram 17L, Dripline 2000, Tiran 17 e Typhoon 20; para tanto, utilizou-se delineamento estatístico em blocos ao acaso em parcela subdividida, constituído de cinco tratamentos (modelo de gotejador) na parcela e tempo de funcionamento ( 9 níveis) na subparcela com quatro repetições. A água utilizada no ensaio provinha de fonte hídrica superficial, utilizada para irrigação, e dela foram isolados diversos gêneros de bactérias, multiplicadas em meio de cultura e utilizadas para manter um nível populacional de bactéria no reservatório da bancada de ensaio superior a $50.000 \mathrm{UFC} \mathrm{mL}^{-1}$, através de inoculações efetuadas quando o número de células decaía a esse patamar. Em intervalos de tempo de funcionamento do sistema de $240 \mathrm{~h}$, a vazão de cada gotejador era medida totalizando um tempo de $2160 \mathrm{~h}$ de operação. Os resultados apontaram diferenças entre os emissores avaliados quanto à ocorrência do entupimento, tendo os modelos Ram e Streamline apresentado os menores níveis de redução de vazão, em relação aos modelos Tiran e Dripline.
\end{abstract}

Palavras-chave: bactéria, obstrução, irrigação por gotejamento

\section{SUSCEPTIBILITY OF DRIPPERS TO BIOLOGICAL CLOGGING}

\begin{abstract}
An experiment was conducted with the objective of evaluating the resistance of different dripper designs for biological clogging. Five kinds of drippers: Streamline 100, Ram 17L, Dripline 2000, Tiran 17 and Typhoon 20 were evaluated. The statistical design used was a completely randomized block in a split plot, composed of 5 treatments (dripper model) in the main plot and operation time (9 levels) in the sub plot with 4 replications. A regular water source for irrigation equipment was used with some bacterial genus and presenting a bacterial population of about $50,000 \mathrm{UFC} \mathrm{mL}^{-1}$. In every $240 \mathrm{~h}$ the flow of each emitter was measured. The total operation time was $2160 \mathrm{~h}$. The results showed that there were differences among the emitters. Ram and Streamline models presented the smaller flow rate reduction while Tiran and Dripline models presented the higher flow rate reduction.
\end{abstract}

Key words: bacteria, clogging, drip irrigation

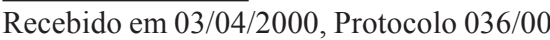

${ }^{1}$ Parte de Dissertação de Mestrado apresentada à Escola Superior de Agronomia “Luiz de Queiroz" - ESALQ, pelo primeiro autor

${ }^{2}$ Eng. Agr. M.Sc. Irrigação e Drenagem, COHIDRO-SE. Doutorando do DER/ESALQ/USP. Av. Pádua Dias, 11, CEP 13.416 - 150, Piracicaba, SP. Fone: (0xx19) 429 4217, Fax: (0xx19) 422 5925. E-mail: rsrezend@carpa.ciagri.usp.br

${ }^{3}$ Professor Doutor do Departamento de Engenharia Rural da ESALQ/USP. Fone: (0xx19) 4294217. E-mail: rdcoelho@carpa.ciagri.usp.br

${ }^{4}$ Professora Doutora do Departamento de Ciências Exatas da ESALQ/USP. Fone: (0xx19) 429 4127. E-mail: soniamsp@carpa.ciagri.usp.br 


\section{INTRODUÇÃO}

Uma característica inerente aos métodos de irrigação localizados, é a pequena área de passagem da água nos emissores. Em função dos pequenos diâmetros de orifício, o entupimento dos emissores configura-se como um dos principais problemas relacionados ao método (Gilbert \& Ford, 1986; Keller \& Bliesner, 1990; Boman \& Ontermaa, 1994; Sagi et al., 1995; Pitts et al., 1996). Em nossas condições, uma combinação de fatores favorece o desenvolvimento de algas e bactérias na água utilizada em irrigação localizada, como: predominância de temperatura na faixa ótima para o desenvolvimento microbiano; uso freqüente da prática de fertirrigação, a qual se constitui em fonte de nutrientes para algas e bactérias; uso freqüente de águas de reservatórios e canais, que favorecem o crescimento populacional de algas e bactérias e altos índices de lançamento de esgotos em rios que servem de fonte hídrica etc. A obstrução de emissores afeta a uniformidade de aplicação de água e, conseqüentemente, reduz a eficiência da aplicação de produtos químicos, via água de irrigação, na mesma proporção da redução de uniformidade de aplicação.

Sagi et al. (1995) determinaram redução de vazão média de gotejadores de $38 \%$ em relação à vazão inicial, em função da presença de mucilagem formada por colônias de protozoário (Epystilys balanarum). Ocorreu redução de $57 \%$ na área de passagem do emissor. Estudando o efeito de diâmetros de orifício na taxa de entupimento de microaspersores, Boman (1995) observou que $20 \%$ dos emissores de $0,76 \mathrm{~mm}$ de diâmetro requereram limpeza, comparado a $14 \%$ dos de $1,02 \mathrm{~mm} ; 7 \%$ dos de $1,27 \mathrm{~mm}$ e $5 \%$ dos de diâmetro de $1,52 \mathrm{~mm}$. Para esse estudo, $46 \%$ dos casos de entupimento foram devidos a algas, $34 \%$ à obstrução por formigas e aranhas, $16 \%$ à obstrução por lesmas e $4 \%$ devido à obstrução física por partículas de areia e pedaços de PVC.

$\mathrm{O}$ entupimento parcial dos emissores, que se constitui o caso mais comumente encontrado em campo, apresenta o inconveniente adicional de não ser perceptível visualmente, $o$ que retarda a tomada de ação para o equacionamento do problema.

Diferentes gotejadores apresentam graus de suscetibilidade diversos ao entupimento, seja em função de características construtivas, hidráulicas ou de mecanismos próprios de autolimpeza. Neste sentido e na perspectiva de utilização de fontes hídricas que apresentem condições críticas quanto a parâmetros de qualidade que envolvam entupimento de emissores, a escolha do tipo de emissor será fator decisivo no elenco de medidas a serem consideradas.

O objetivo deste trabalho foi avaliar a suscetibilidade de diferentes tipos de gotejadores comumente utilizados no
Brasil, ao entupimento de origem biológica e os principais microrganismos envolvidos.

\section{MATERIAL E MÉTODOS}

O experimento foi conduzido no Laboratório de Irrigação do Departamento de Engenharia Rural, da Escola Superior de Agricultura "Luiz de Queiroz" - ESALQ/USP, localizada no município de Piracicaba, SP, no período de maio a outubro de 1999.

Foram avaliadas cinco diferentes famílias de gotejadores, da marca comercial Netafim, comumente utilizados em sistemas implantados no Brasil, quais sejam: Ram 17L (RAM), Streamline 100 (SL), Tiran 17 (TR), Typhoon 20 (TY) e Dripline 2000 (DL). Todos os emissores utilizados são do tipo câmara simples, percurso tortuoso, fluxo turbulento e apresentaram, em ensaios preliminares, coeficiente de uniformidade de fabricação-CV, inferior a $5 \%$ e os dados técnicos relativos a cada modelo de emissor utilizado encontram-se na Tabela 1.

A água empregada durante o experimento proveio de lago utilizado como fonte hídrica, para um projeto de irrigação por gotejamento, no município de Sumaré, SP e, juntamente com a contagem da população bacteriana existente, foram isolados diferentes gêneros não identificados de bactérias e multiplicados em meio de cultura, sendo estes isolados utilizados para futuras inoculações na água do reservatório da bancada do experimento.

Para a condução do experimento construiu-se uma bancada em madeira (Figura 1) com dimensões de $6 \mathrm{~m}$ de comprimento $\mathrm{x}$
(A)

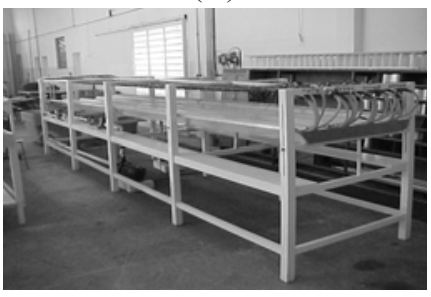

(C)

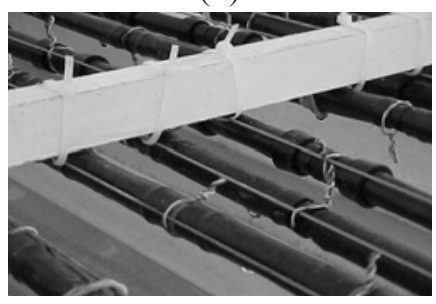

(B)

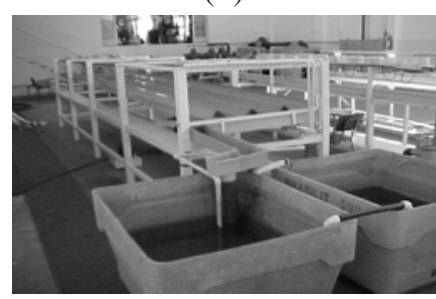

(D)

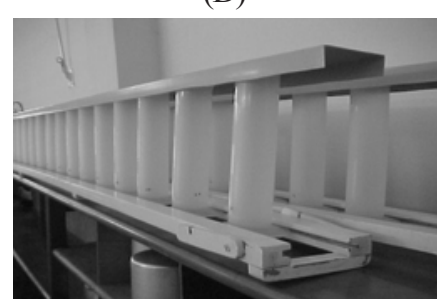

Figura 1. Visão geral da bancada de ensaio (A) e (B); detalhe das mangueiras remontadas por conectores, alinhadas por meio de cabo de aço e com barbante para direcionar as gotas nas provetas $(\mathrm{C})$ e bateria de provetas usadas na determinação das vazões individuais dos gotejadores (D)

Tabela 1. Características dos gotejadores estudados

\begin{tabular}{|c|c|c|c|c|c|c|}
\hline Código & Modelo & $\begin{array}{l}\text { Vazão } \\
\left(\mathrm{Lh}^{-1}\right)\end{array}$ & $\begin{array}{c}\text { Pressão } \\
(\mathrm{kPa})\end{array}$ & $\begin{array}{l}\text { Diâmetro Orifício } \\
(\mathrm{mm})\end{array}$ & $\begin{array}{c}\text { Espessura } \\
\text { da Parede (mm) }\end{array}$ & $\begin{array}{c}\text { Diâmetro } \\
\text { Interno }(\mathrm{mm})\end{array}$ \\
\hline SL 100 & STREAMLINE 100 & 1,60 & 100 & 0,53 & 0,25 & 16,0 \\
\hline RAM 17 & RAM $17 \mathrm{~L}$ & 2,30 & 100 & 1,04 & 0,62 & 14,6 \\
\hline TR 16 & TIRAN 17 & 2,00 & 100 & 1,38 & 1,20 & 14,6 \\
\hline TY 20 & TYPHOON 20 & 1,75 & 100 & 0,71 & 0,50 & 15,4 \\
\hline
\end{tabular}


1,3 m de largura e 1,45 m de altura. A estrutura hidráulica foi constituída de quatro blocos e em cada um foram instaladas cinco linhas de gotejadores de cada modelo (Figura 2); por outro lado, cada linha foi composta de 50 gotejadores, o que resultou na avaliação de um total de 200 gotejadores de cada modelo; para isto, as mangueiras com espaçamento original entre emissores foram cortadas e remontadas, utilizando-se uniões de mangueira, resultando em um espaçamento único entre gotejadores, de $0,11 \mathrm{~m}$ para todos os modelos. A água, após passar através dos gotejadores, era recolhida por uma calha que a reconduzia ao tanque de captação, constituindo, assim, um sistema de recirculação de água (Figura 1A e 1B).

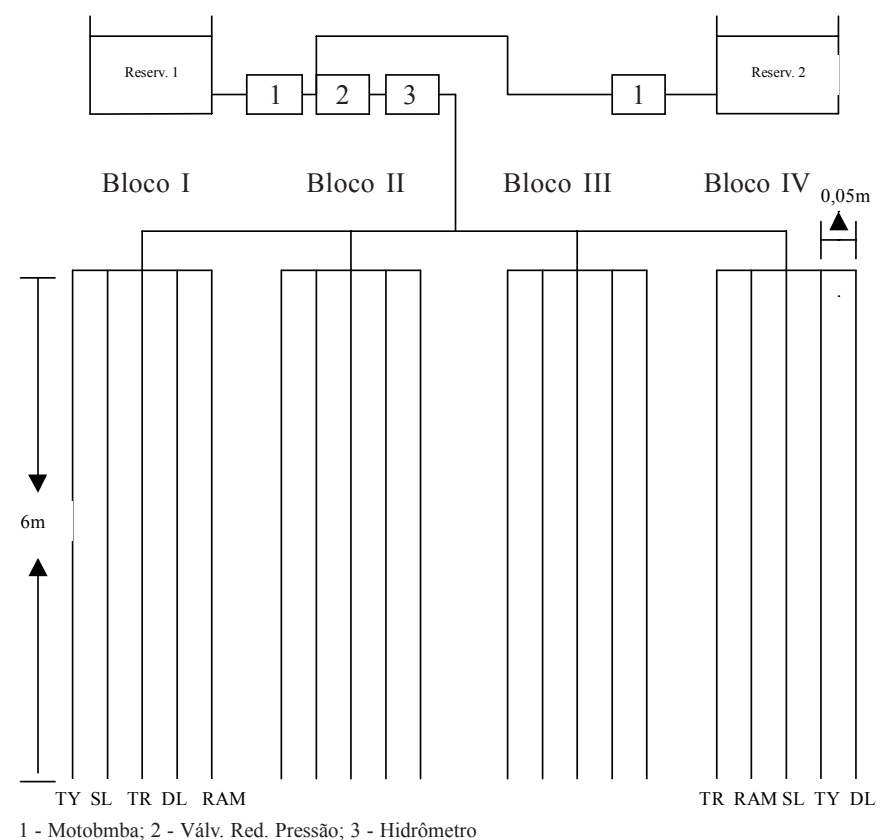

1 - Motobmba; 2 - Válv. Red. Pressão; 3 - Hidrômetro

Figura 2. Esquema geral da bancada do experimento

A cada dois dias era efetuada uma contagem populacional da água coletada nos tanques da bancada de experimento. A determinação da população bacteriana foi efetuada através do método de contagem em placa de Petri (HPC) utilizando-se ágar (triptona, glucose, extrato de levedura e ágar) como meio de cultura e tempo para contagem de 48 h, (APHA, 1992a); quando o nível populacional decrescia abaixo de 50.000 unidades formadoras de colônias por mililitro de água (UFC m L $\mathrm{L}^{-1}$ ), considerado como o nível a partir do qual o risco de entupimento se torna severo (Bucks \& Nakayama, 1980, apud por Gilbert \& Ford, 1986), o meio de cultura com o conjunto de bactérias isoladas era inoculado no reservatório.

A pressão de serviço foi mantida em $100 \pm 10 \mathrm{kPa}$, por meio de válvula redutora de pressão, colocada à entrada da linha principal da bancada. No sentido de agilizar a medição da vazão direta dos gotejadores, montou-se uma estrutura de madeira, que permitia a inserção de uma bateria de 50 provetas graduadas de $250 \mathrm{~mL}$.

Ao final de cada linha de gotejadores instalou-se um registro de gaveta, com o objetivo de regular a vazão na lateral, para um valor médio aproximadamente igual ao que seria encontrado no terço final de uma linha lateral em nível, com emissores idênticos, igualmente espaçados e comprimento máximo, para uma variação de vazão de $10 \%$; tal procedimento visava proporcionar vazões nas laterais compatíveis com aquelas normalmente encontradas em campo, evitando-se velocidades excessivamente baixas. Durante a medição, o registro de gaveta era fechado, no sentido de não interferir no valor da pressão daqueles emissores localizados próximo aos mesmos.

O experimento teve duração de 4 meses, totalizando $2160 \mathrm{~h}$ de funcionamento do sistema. A operacionalização do funcionamento da bancada, quanto ao horário de início e de parada, foi efetuada através de um controlador de irrigação, o qual foi utilizado no acionamento do conjunto motobomba elétrica, visando a um funcionamento em 8 ciclos diários, correspondendo a duas horas de funcionamento e intervalos de $1 \mathrm{~h}$, totalizando $16 \mathrm{~h}$ por dia. Os horários estabelecidos foram: $00: 00$ às $2: 00 ; 3: 00$ às $5: 00 ; 6: 00$ às $8: 00 ; 9: 00$ às $11: 00$; $12: 00$ às $14: 00 ; 15: 00$ às $17: 00 ; 18: 00$ às $20: 00 ; 21: 00$ às $23: 00$, para todos os dias da semana.

As medições individuais da vazão dos gotejadores foram efetuadas quinzenalmente, correspondendo a intervalos de $240 \mathrm{~h}$ de funcionamento do sistema, totalizando dez medições no período do experimento. Ao se efetuar a medição das vazões com o uso de bateria de provetas (Figura 1D) cada gotejador era cuidadosamente observado, no sentido de não haver interferência de vazões provenientes de gotejadores adjacentes e/ou de pontos de conexão; para tanto, barbantes foram utilizados para isolar a vazão de cada gotejador e, então, os volumes eram coletados por um período de tempo de $5 \mathrm{~min}$. Uma calha retangular de PVC foi utilizada para cobrir, ao mesmo tempo, a bateria de provetas no momento da leitura (Figura 1D).

À entrada de cada bloco foi instalada uma tomada de pressão, permitindo que a cada medição de vazão a pressão fosse checada e, se necessário, ajustada àquela preestabelecida. Para a medição da pressão de serviço, à entrada da linha de emissores utilizou-se um manômetro tipo Bourdon, o qual foi aferido mensalmente. Com o objetivo de se monitorar o nível de aquecimento da água na bancada, devido à recirculação da água no sistema e evitar temperaturas acima do ótimo para o crescimento bacteriano, efetuaram-se leituras diárias da temperatura da água na bancada do experimento.

Mensalmente e ao final do experimento, eram removidos emissores, independente do modelo, apresentando maior grau de entupimento e analisados em laboratório para a identificação genérica dos organismos formadores de mucilagem; o tempo decorrido entre a coleta do emissor e a inoculação em placa de Petri, não era maior que duas horas, período em que as amostras eram mantidas em recipiente térmico com gelo; ainda mensalmente, eram efetuadas coletas de água à saída dos gotejadores, para fins de análise de $\mathrm{pH}$, condutividade elétrica, $\mathrm{Fe}^{2+}, \mathrm{Mn}^{2+}, \mathrm{Ca}^{2+}, \mathrm{Mg}^{2+}, \mathrm{CO}_{3}{ }^{2-}, \mathrm{HCO}_{3}^{-}, \mathrm{Cl}^{-}, \mathrm{SO}_{4}{ }^{2-}, \mathrm{NO}_{3}^{-}$, e sólidos suspensos. Com base nos resultados da análise química da água, foi calculado o Índice de Saturação de Langelier (ISL) baseados nos teores de $\mathrm{Ca}^{2+}, \mathrm{Mg}^{2+}, \mathrm{HCO}_{3}^{-}$e $\mathrm{CO}_{3}^{2-}$, no sentido de prover uma aproximação sistemática para a determinação do risco natural de formação de precipitados de carbonato de cálcio, conforme metodologia proposta pelo Bower et al. (1965).

Para efeito de avaliação da eficiência dos tratamentos, analisaram-se os seguintes parâmetros: a) vazão média dos emissores, para os tempos de operação de $240,480,720,960$, $1200,1440,1680,1920$ e $2160 \mathrm{~h}$, expressa como percentual do 
valor nominal; b) percentual do número total de emissores, para cada modelo, por faixa de redução de vazão, sendo essas faixas estabelecidas como: $<5 \%$ (considerado como sem entupimento), 5 - 15\%, 15 - 25\%, 25 - 35\%, 35 - 45\%, 45 - 55\%, $55-65 \%, 65-75 \%, 75-85 \%, 85-95 \%$ e $>95 \%$ (considerado como completamente entupido) da vazão nominal do gotejador e c) coeficiente de variação de vazão de emissores individuais $\left(\mathrm{CV}=100 \mathrm{sd} / \mathrm{q}_{\mathrm{m}}\right)$ donde sd é o desvio-padrão das vazões medidas e $\mathrm{q}_{\mathrm{m}}$, a vazão média dos gotejadores.

A parcela experimental consistiu de uma linha lateral, com gotejadores espaçados $0,11 \mathrm{~m}$, totalizando o comprimento de $6 \mathrm{~m}$ (50 emissores por linha); cada linha de gotejador foi composta por apenas um modelo. Adotou-se um delineamento estatístico em blocos inteiramente casualizados, em parcelas subdivididas, sendo tempo de operação a subparcela (9 níveis), com cinco tratamentos (modelos de gotejadores) e quatro repetições, além da utilização dos testes "F" para a análise de variância e Tukey, a nível de 5\% de probabilidade, para comparação de médias.

\section{RESULTADOS E DISCUSSÃO}

Os teores de $0,05 \mathrm{mg} \mathrm{L}^{-1}$ de $\mathrm{Fe}^{2+}, 0,01 \mathrm{mg} \mathrm{L}^{-1}$ de $\mathrm{Mn}^{+2}$, elementos químicos relacionados a risco entupimento, encontram-se bem abaixo dos valores indicados como limite de risco mínimo, por Bucks \& Nakayama (1980) citados por Gilbert \& Ford (1986) ocorrendo o mesmo para o teor de sólidos em suspensão, com valor de $2 \mathrm{mg} \mathrm{L}^{-1}$. Na análise de caracterização da água, a contagem bacteriana resultou em valor de 3,5 x $10^{3}$ UFC $\mathrm{mL}^{-1}$, a qual se configura, também, como de baixo risco ao entupimento de emissores.

O ISL calculado para a água utilizada resultou em valor negativo, indicando não haver tendência de precipitação de carbonato de cálcio e conseqüente potencial de entupimento, por tal composto químico; embora apresentando limitações, tal índice é o mais comumente usado (American Public Health Association, 1992b).

A população bacteriana na água variou de $3,2 \times 10^{2} \mathrm{UFC} \mathrm{mL}^{-1}$ a $1,0 \times 10^{6} \mathrm{UFC} \mathrm{mL}^{-1}$ (Figura 3 ) ficando, durante quase todo o período do experimento, acima do valor inicial do nível considerado severo por Nakayama \& Bulks (1980) citados por Gilbert \& Ford (1986). Durante o experimento, ocorreram decréscimos ocasionais no nível populacional por curtos períodos, tendo sido relacionados com limpeza efetuada no fundo do reservatório, o que provavelmente reduzia o nível de nutrientes na água. Após a adição de uma solução de glicose e peptona, como fonte de carbono e nitrogênio, respectivamente, a população retornava à faixa de valores preestabelecidos.

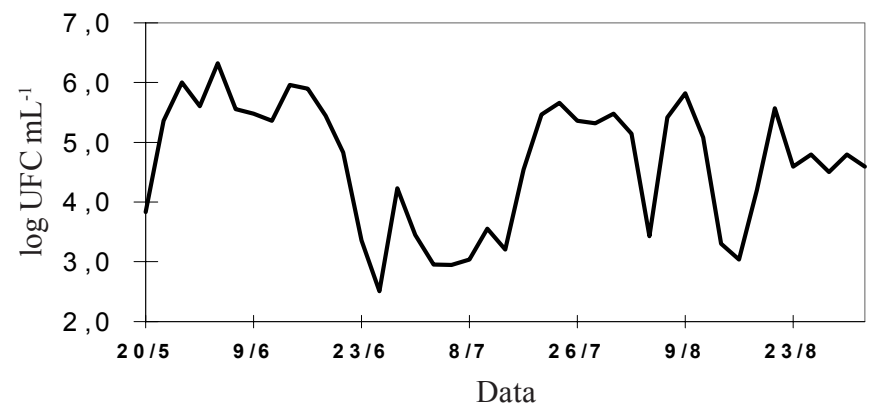

Figura 3. Nível populacional de bactérias na água do reservatório, no período do experimento

\section{Vazão média dos emissores}

Do ponto de vista prático, a vazão média de emissores pode ser considerada um bom parâmetro para avaliar o processo de entupimento, sendo utilizado em todos os trabalhos pertinentes (Gilbert et al.,1979; Nakayama et al.,1977; Ravina et al., 1992). Os valores de vazão apresentados referem-se à média de 200 gotejadores, para cada modelo.

Os emissores avaliados apresentaram comportamento diferenciado quanto à redução de vazão, em função do entupimento (Figura 4). Para permitir a comparação do grau de redução de vazão entre os modelos de emissores, uma vez que os mesmos apresentam vazões nominais diferentes, a análise de variância foi efetuada proporcionalizando a vazão medida em relação à nominal. Os resultados da análise de variância e do teste de comparação de médias entre modelos de gotejador e número de horas de operação do sistema, encontram-se nas Tabelas 2 e 3 .

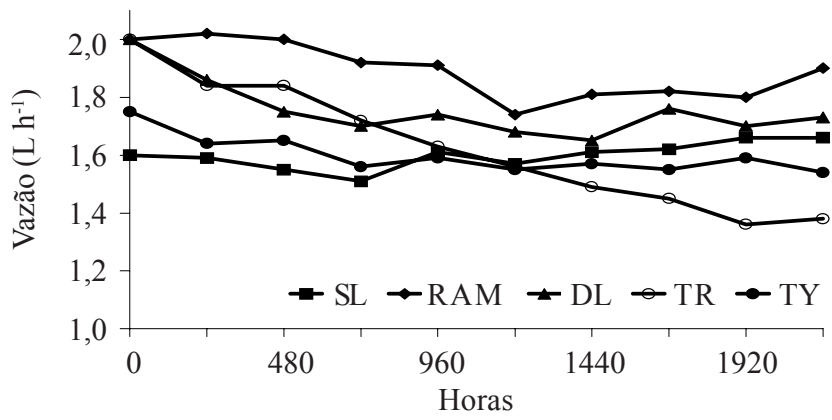

Figura 4. Variação da vazão média dos gotejadores no período do experimento

O modelo Streamline apresentou o melhor desempenho, praticamente não variando a vazão, no período do experimento. Até o tempo de funcionamento de 960 h, não foi observada diferença significativa de redução de vazão entre os gotejadores Ram e Streamline, mas a partir de 1200 h, o modelo Streamline mostrou-se estatisticamente superior ao Ram e aos demais gotejadores, até o final do experimento, comportamento este não esperado, basicamente em função de dois aspectos: a) por se tratar de um modelo de gotejador com menor especificação de vida útil, indicado para uso por 2 a 4 safras de cultivo, o que lhe imprime caráter descartável; no entanto, esta característica pode estar mais vinculada à durabilidade em campo, em função da espessura de parede da mangueira, que ao gotejador em si; b) porque, dentre todos os emissores avaliados, é aquele que apresenta menor diâmetro do orifício de passagem de água, com $0,53 \mathrm{~mm}$, característica esta preponderante na suscetibilidade ao entupimento, conforme estabelecido em trabalho de Boman (1995) onde emissores com diferentes diâmetros de orifício, foram avaliados quanto à ocorrência de entupimento de origens diversas.

De modo contrário ao modelo Streamline, o modelo Tiran, o qual apresenta o maior diâmetro de orifício de passagem, com $1,38 \mathrm{~mm}$, foi aquele que apresentou maior redução de vazão média. Os modelos Tiran e Dripline apresentaram desempenho mais negativo, diferindo estatisticamente, a partir do tempo de 1440 h, com redução máxima de 32 e 18\%, respectivamente, no período do experimento. Para os demais modelos, esses valores 
Tabela 2. Resumo da análise de variância e teste de comparação de médias de percentual da vazão nominal entre modelos de gotejadores

\begin{tabular}{|c|c|c|c|c|c|c|c|c|c|}
\hline \multirow[b]{2}{*}{ Modelo } & \multicolumn{9}{|c|}{ Número de Horas de Operação do Sistema" } \\
\hline & 240 & 480 & 720 & 960 & 1200 & 1440 & 1680 & 1920 & 2160 \\
\hline SL & $99,3 \mathrm{AB}$ & $96,8 \mathrm{AB}$ & $94,2 \mathrm{~A}$ & $100,3 \mathrm{~A}$ & $98,2 \mathrm{~A}$ & $100,8 \mathrm{~A}$ & $101,4 \mathrm{~A}$ & $103,9 \mathrm{~A}$ & $103,7 \mathrm{a} \mathrm{A}$ \\
\hline RAM & $101,0 \mathrm{~A}$ & $100,1 \mathrm{~A}$ & $96,0 \mathrm{~A}$ & $95,6 \mathrm{AB}$ & $86,7 \mathrm{BC}$ & $90,6 \mathrm{~B}$ & $91,1 \mathrm{~B}$ & $90,0 \mathrm{~B}$ & $94,7 \mathrm{~b} \mathrm{~B}$ \\
\hline DL & $92,6 \mathrm{~B}$ & $87,6 \mathrm{C}$ & $85,0 \mathrm{~B}$ & $86,7 \mathrm{D}$ & $83,8 \mathrm{C}$ & $82,6 \mathrm{C}$ & $88,1 \mathrm{~B}$ & $85,0 \mathrm{~B}$ & $86,6 \mathrm{c} \mathrm{C}$ \\
\hline TR & $91,8 \mathrm{~B}$ & $92,0 \mathrm{C}$ & $86,0 \mathrm{~B}$ & $81,2 \mathrm{D}$ & $78,0 \mathrm{C}$ & $74,6 \mathrm{D}$ & $72,5 \mathrm{C}$ & $68,0 \mathrm{C}$ & $68,7 \mathrm{~d} D$ \\
\hline TY & $93,6 \mathrm{~B}$ & $94,4 \mathrm{BC}$ & 89,6 B & $90,6 \mathrm{C}$ & $88,4 \mathrm{~B}$ & 89,6 B & 87,7 B & $90,5 \mathrm{~B}$ & $88,1 \mathrm{c} \mathrm{BC}$ \\
\hline Valor F & $8,71 * *$ & $13,6^{* *}$ & $18,2 * *$ & $32,3 * *$ & $21,9 * *$ & $71,8 * *$ & $53,8 * *$ & $47,2 * *$ & $93,1 * *$ \\
\hline
\end{tabular}

* Médias seguidas da mesma letra, dentro de uma mesma coluna, não diferem a nível de $1 \%$ pelo teste de Tukey

** Significativo a nível de $1 \%$ de probabilidade

Tabela 3. Comparação das médias de percentual da vazão nominal entre tempo de operação do sistema

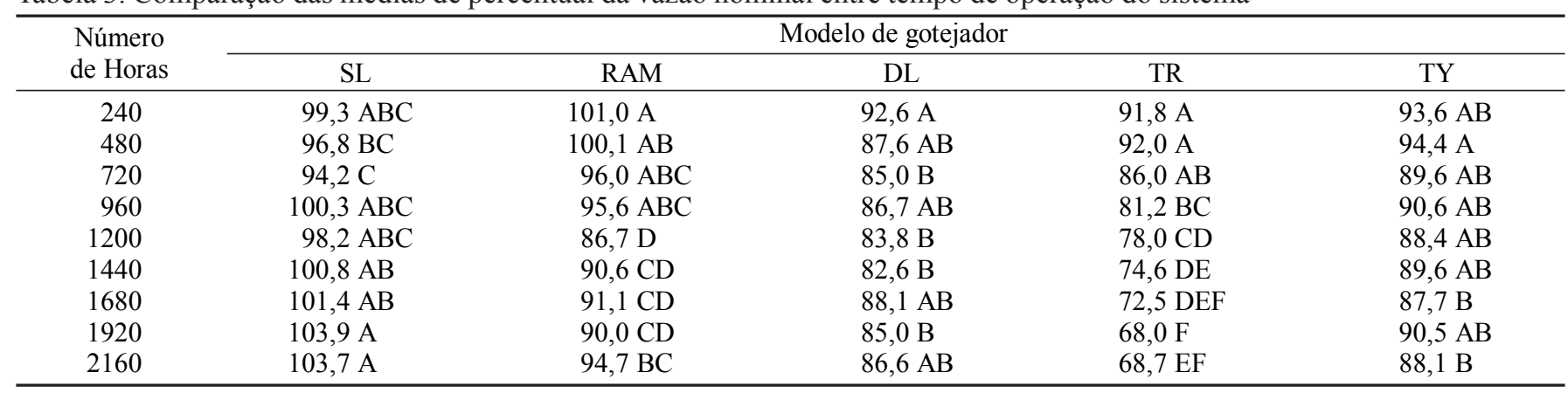

Médias seguidas da mesma letra, dentro de uma mesma coluna, não diferem a nível de $1 \%$ pelo teste de Tukey

**Significativo a nível de $1 \%$ de probabilidade

foram: $13 \%$ para o Ram e 12\% para o Typhoon, os quais diferiram somente para os tempos de funcionamento de 240, 720 e 2160 h, a nível de $1 \%$ de significância.

O gotejador Tiran, embora possua o maior diâmetro do orifício de passagem de água, caracteriza-se por apresentar, dentre os modelos avaliados, o maior percurso de caminhamento da água (129 mm) conforme especificado na Tabela 4, aliado a uma relativamente pequena área de filtragem. O longo percurso pode ter favorecido o desenvolvimento de mucilagem ou um processo contínuo de deposição de material em suspensão, na parte interna do emissor, determinando a uniformidade com que se deu a redução de vazão ao longo do período do ensaio.

Para a maior parte dos modelos, ocorreram reduções de vazão significativas entre épocas de amostragem, como se verifica na Tabela 3; nesse aspecto, o gotejador Streamline constituiu exceção, uma vez que a vazão média apresentou aumento ao longo do experimento, sendo que as épocas de 1920 e $2160 \mathrm{~h}$ de operação foram estatisticamente superiores às demais. Nos modelos Ram e Dripline, reduções significativas de vazão, da ordem de 5 e $14 \%$, respectivamente, ocorreram a partir de 960 h, embora apresentando recuperação na vazão ao final do experimento. Para o gotejador Typhoon, uma redução significativa de vazão aconteceu mais tardiamente, a partir de 1200 h de operação. A redução de vazão mais uniforme se deu com o gotejador Tiran, a qual mostrou diferença significativa entre quase todas as épocas de amostragem.

O bom desempenho do modelo Streamline, em termos de manutenção de vazão ao longo do experimento, mesmo apresentando menor diâmetro de orifício de passagem de água, pode estar relacionado ao relativo elevado tamanho da área de filtragem de água, como também às características de fluxo e ao pequeno comprimento do percurso da água no interior do emissor. O gotejador Dripline, que se destacou em função do mais elevado número de emissores com entupimento total apresenta, por sua vez, juntamente com o modelo Typhoon, percurso de água superior ao Streamline e reduzida área de filtragem

O modelo Ram, que também foi destaque pelo nível de manutenção de vazão e uniformidade de aplicação de água, além da característica de auto-limpeza, tem seu orifício de entrada de água elevado, posicionando-se praticamente no centro da seção transversal da mangueira onde, supostamente, a água se encontra com menor nível de resíduo. Este aspecto, o qual necessita ser melhor avaliado em estudos posteriores, pode ser parcialmente manejado em campo, posicionando-se o emissor sempre voltado para cima, na linha lateral.

Tabela 4. Características do labirinto de passagem de água e filtro de água, dos emissores avaliados

\begin{tabular}{ccccc}
\hline Modelo & $\begin{array}{c}\text { Profundidade } \\
(\mathrm{mm})\end{array}$ & $\begin{array}{c}\text { Largura } \\
(\mathrm{mm})\end{array}$ & $\begin{array}{c}\text { Comprimento } \\
(\mathrm{mm})\end{array}$ & $\begin{array}{c}\text { Comprimento do Filtro } \\
(\mathrm{mm})\end{array}$ \\
\hline SL & $\mathrm{ND}$ & $\mathrm{ND}$ & $\mathrm{ND}$ & ND \\
RAM & 1,04 & 1,04 & 15 & ND \\
DL & $\mathrm{ND}$ & $\mathrm{ND}$ & $\mathrm{ND}$ & $\mathrm{ND}$ \\
TR & 0,93 & 0,97 & 129 & 16,7 \\
TY & 0,71 & 0,71 & 20 & ND \\
\hline
\end{tabular}

ND - Informação não disponível em catálogo técnico 
O modelo Ram, diferentemente dos demais, apresentou vazão inicial de $2,0 \mathrm{~L} \mathrm{~h}^{-1}$, bem abaixo da sua vazão nominal, de $2,3 \mathrm{~L} \mathrm{~h}^{-1}$. Tal comportamento pode estar relacionado à influência dos conectores de união, espaçados $0,11 \mathrm{~m}$, junto às membranas de compensação de pressão do emissor. Em ensaios preliminares em que se utiliza o espaçamento original, a vazão observada do modelo foi a nominal. Este gotejador foi o único a apresentar tal comportamento e o único, também, com característica autocompensante. A redução da vazão foi, contudo, uniforme para todos os emissores, evidenciada pelo baixo valor do $\mathrm{CV}$ inicial; desta forma, a vazão de $2,0 \mathrm{~L} \mathrm{~h}^{-1}$ foi considerada como sendo a vazão nominal para este gotejador.

Oron et al. (1979) observaram percentuais de redução de vazão de até 29\%, utilizando água residuária. Sagi et al. (1995) encontraram reduções de até $38 \%$ em relação à vazão inicial, causadas por mucilagem do protozoário Epystilys balanarum, com reduções de até 57\% na área de passagem de água do emissor. Nakayama et al. (1977) observaram reduções de vazão de 25 a $50 \%$, causadas principalmente por mucilagem de bactéria, não identificada por estes autores, em gotejadores com 2 anos de funcionamento.

\section{Uniformidade de aplicação de água}

O coeficiente estatístico de variação de vazão $(\mathrm{CV})$ determinado pelo desvio-padrão dos valores de vazão da amostra, em relação à vazão média, representa uma medida de dispersão relativa dos dados e, quando aplicado em uma amostra de emissores novos, é definido como o coeficiente de variação de fabricação, o qual representa pequenas diferenças construtivas de cada emissor (Solomon, 1979). Todos os emissores avaliados apresentaram coeficiente de variação inicial de vazão inferior a $5 \%$. Dada a pequena magnitude de fatores causadores de desuniformidade (perdas de carga, declividade e diferencial de temperatura da água) e uma vez determinado o valor do CV no início do experimento, as diferenças encontradas no decorrer do experimento foram relacionadas ao processo de entupimento dos emissores. Para todos os tipos de gotejadores, o CV apresentou tendência de crescimento, ao longo do período estudado, tendo sido ele mais pronunciado para os modelos Dripline, Streamline e Typhoon, como se pode verificar através da Figura 5, enquanto o gotejador Ram apresentou o melhor comportamento, mantendo baixos valores de $\mathrm{CV}$ durante todo o período.

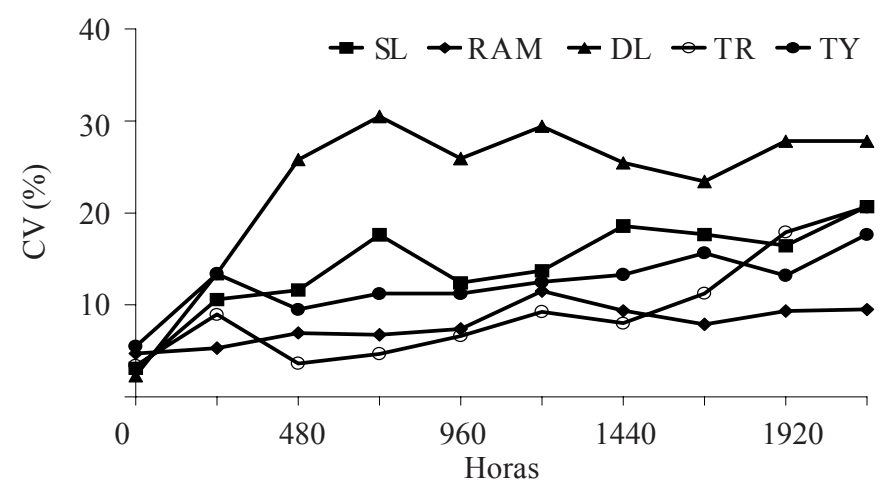

Figura 5. Coeficiente de variação de vazão (CV) no período do experimento
O gotejador Tiran, embora apresentando os maiores valores de redução de vazão média, alcançando até $32 \%$ no período avaliado, apresentou o melhor desempenho com respeito ao $\mathrm{CV}$, até o tempo de operação de $1680 \mathrm{~h}$, indicando que a redução de vazão se deu uniformemente para todos os emissores nas linhas laterais. O aumento observado a partir de $1680 \mathrm{~h}$ resultou em um valor final de 20,65\%, similar ao do Streamline, sendo superior apenas o modelo Dripline. De modo contrário, o modelo Streamline, embora se destacando por não apresentar redução significativa de vazão, apresentou uma perda crescente de uniformidade no decorrer do experimento, sendo seu CV final inferior apenas ao do modelo Dripline.

\section{Distribuição do entupimento}

O percentual de emissores entupidos refere-se ao total de cada modelo, ou seja, 200 gotejadores. A Figura 6 mostra, para os diferentes tipos de emissores, a distribuição percentual do número de emissores para diferentes faixas de redução de vazão. Neste caso, embora se discuta com base nas 10 leituras efetuadas, por uma questão de espaço são apresentadas figuras referentes apenas às etapas inicial e final do experimento. Uma vez que manteve a vazão média praticamente constante durante todo o experimento, o modelo Streamline mostrou o melhor desempenho, tendo $90 \%$ do total dos emissores não apresentado redução de vazão e os $10 \%$ restantes, reduções entre 10 e $20 \%$, enquanto o modelo Ram, que manteve o mesmo comportamento do Streamline até o tempo de operação de $720 \mathrm{~h}$ apresentou, a partir daí, um processo gradativo de entupimento parcial, causando redução de vazão de 10 e $20 \%$ em 56 e 24\% dos emissores do modelo, no tempo de operação de $1200 \mathrm{~h}$.

O padrão de distribuição do nível de entupimento para os modelos Dripline e Typhoon, foi semelhante ao observado para o gotejador Ram sendo, no entanto, mais rápido, iniciando-se já a partir de $240 \mathrm{~h}$ de operação, para ambos os modelos. O maior nível de entupimento foi alcançado pelo gotejador Tiran, tendo-se iniciado a partir de $240 \mathrm{~h}$ de funcionamento e aumentado gradativamente, atingindo $40 \%$ em 16\% do número total de gotejadores, ao final do experimento. Este modelo, no entanto, juntamente com o gotejador Ram, apresentou, durante todo o período de experimento, o menor percentual de gotejadores com entupimento total, ou seja, redução de mais de 95\% da vazão nominal. Os gotejadores Streamline e Typhoon apresentaram comportamento similar quanto ao entupimento total, com valor médio de $1 \%$ do total de emissores de cada modelo.

A análise para a identificação dos gêneros de bactérias presentes no orifício de entrada, na parte interna e na saída do emissor, foi efetuada com pesquisa para os gêneros Clostridium, Bacillus e Pseudomonas, citadas por Gilbert \& Ford (1986) como, entre outras, de principal ocorrência em emissores entupidos. Nas análises efetuadas, somente o gênero Bacillus, gênero de bactéria em forma de cocos flagelados, com larga habilidade fisiológica com respeito ao calor, ao $\mathrm{pH}$ e à salinidade, podendo ser anaeróbia, ou facultativamente anaeróbia (Holt et al., 1994) foi detectado. Gilbert et al. (1982) encontraram predominância da ocorrência deste gênero de bactéria em água do Rio Colorado, EUA, e em emissores de sistemas de irrigação 

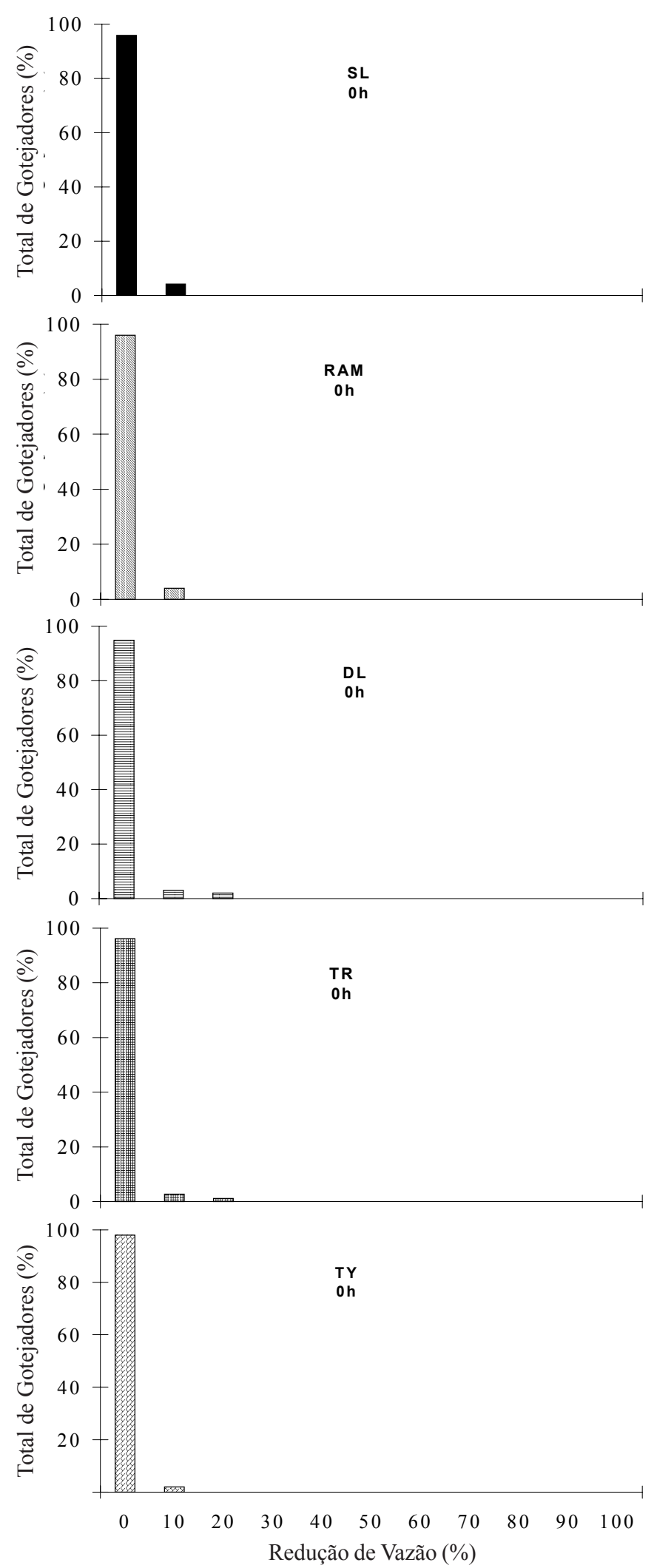
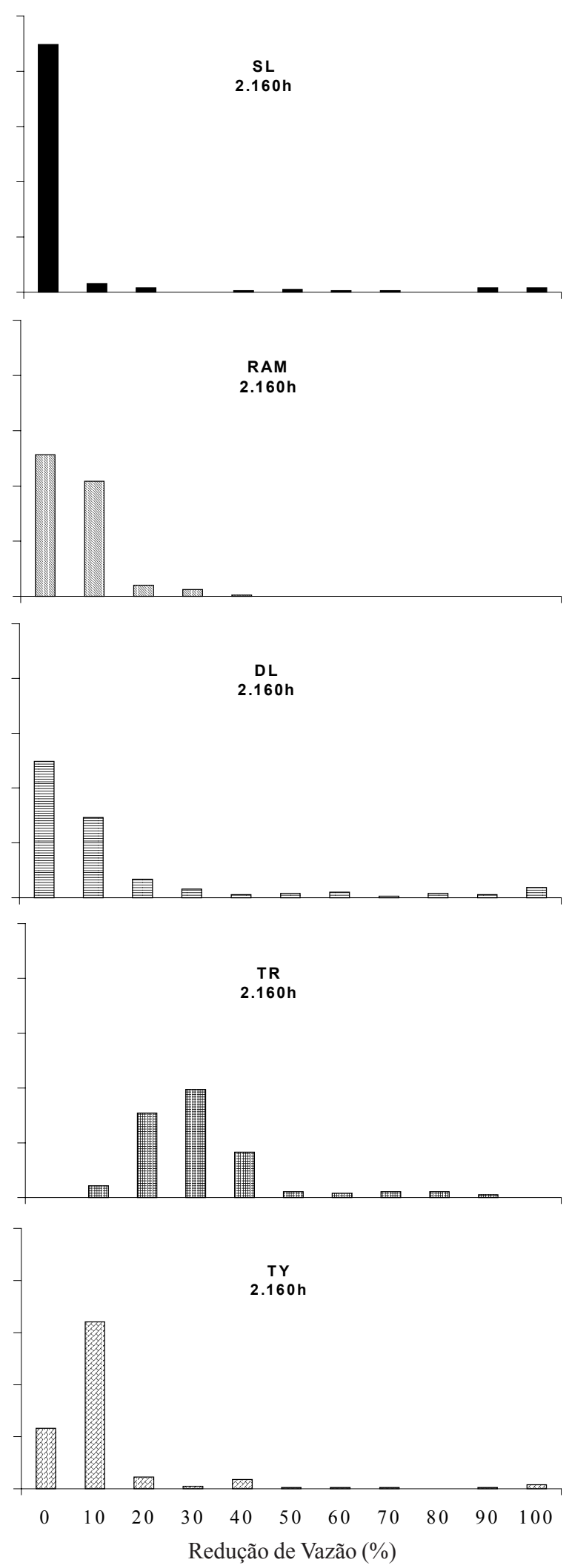

Figura 6. Percentual do número total de gotejadores $(n=200)$ por faixa de redução de vazão

que utilizavam essa água. Observou-se visualmente, na área interna das mangueiras, junto aos emissores ensaiados, a formação de mucilagem, a qual pode ter agido como agente cimentante, para partículas de silte e argila. Não foi observada, a olho nu, a formação de hifas no interior das mangueiras, o que se explica pelo fato de o gênero Bacillus não ser constituído por bactérias filamentosas.

\section{CONCLUSÕES}

Os resultados obtidos na condução do ensaio permitiram evidenciar:

1. Diferenças significativas entre os modelos de gotejadores avaliados, com relação à suscetibilidade ao entupimento de origem biológica. 
2. Os modelos Ram e Streamline apresentaram os menores níveis de redução de vazão, em relação aos modelos Tiran e Dripline.

3. O entupimento parcial foi preponderante em relação ao entupimento total.

4. O entupimento de causa biológica mostrou-se mais relacionado à arquitetura interna dos emissores que a parâmetros de vazão e diâmetro do orifício.

\section{REFERÊNCIAS BIBLIOGRÁFICAS}

APHA - American Public Health Association. Heterotrophic plate count. In: Standard methods for examination of water and wastewater. Washington: APHA, 1992a. p.9.32-9.34.

APHA - American Public Health Association. Calcium carbonate saturation In: Standard methods for examination of water and wastewater. Washington: APHA, 1992b. p.2.28-2.34.

BOMAN, B.J. Effects of orifice size on microsprinkler clogging rates. Transactions of the ASAE, St. Joseph, v.11, n.6, p.839$843,1995$.

BOMAN, B.; ONTERMAA, E. Citrus microsprinkler clogging: Costs, causes, and cures. Procedure: Florida State Horticultural Society, n.107. p.39-47, 1994.

BOWER, C.A.; WILCOX, L.V.; AKIN, G.W.; KEYES, M.G. Department of Agriculture. An index of the tendency of $\mathrm{CaCO}_{3}$ to precipitate from irrigation waters. Soil Science Society of America Proceedings, Madison, v.29, p.91-92, 1965.

GILBERT, R.G.; FORD, H.W. Operational principles/emitter clogging. In: NAKAYAMA, F.S.; BULKS, D.A. Trickle irrigation for crop production . Amsterdam: Elsevier, 1986. cap.3. p.142-163.

GILBERT, R.G.; NAKAYAMA, F.S.; BUCKS, D.A. Trickle irrigation: prevention of clogging. Transactions of the ASAE, St. Joseph, v.22, p.514-519, 1979.
GILBERT, R.G.; NAKAYAMA, F.S.; BUCKS, D.A.; FRENCH, O.F.; ADAMSON, K.C.; JOHNSON, R.M. Trickle irrigation: Predominant bacteria in treated Colorado River water and clogged emitters. Irrigation Science, New York, v.3, p.123-132, 1982.

HOLT, J.G.; KRIEG, N.R; SNEATH, P.H.A; NICHOLAS, S.M.; SHARPE, M.E.; STALEY, J.T.; BRYANT, M.P.; PFENNING, N; WILLIAMS, S.T. Bergey's manual of determinative bacteriology. 9 ed. Baltimore: Williams e Wilkins, 1994. 787p.

KELLER, J.; BLIESNER, D.R. Sprinkler and trickle irrigation. New York: von Nostrand Reinhold, 1990. 652p.

NAKAYAMA, F.S. Operational principles/water treatment. In: NAKAYAMA, F.S.; BULKS, D.A. Trickle irrigation for crop production . Amsterdam: Elsevier, 1986. cap.3, p.164-187.

NAKAYAMA, F.S.; BUCKS, D.A.; FRENCH, O.F. Reclaiming partially clogged trickle emitters. Transactions of the ASAE, St Joseph, v.20, p.278-280, 1977.

ORON, G.; GEDALIAH, S.; ZUR, B. Stormwater and recalimed effluent for trickle irrigation. Journal of Irrigation and Drainage Division ASCE, Reno, v.108, n.2, p.115-126, 1979.

PITTS, D.; PETERSON, K.; GILBERT, G.; FASTENAU, R. Field assessment of irrigation system performance. Transactions of the ASAE, St. Joseph, v.12, n.3, p.307-313, 1996.

PIZARRO, F. Riegos localizados de alta frequencia. 3ed. Madrid: Ed. Mundi Prensa, 1996. 513p.

RAVINA, I.; PAZ, E.; SOFER, Z; MARCU, A; SHISHA, A; SAGI, G. Control of emitter clogging in drip irrigation with reclaimed wastewater. Irrigation Science, New York, v.13. p.129-139, 1992.

SAGI, G.; PAZ, E.; RAVINA, I; SCHISCHA, A; MARCU, A; YECHIELY, Z. Clogging of drip irrigation systems by colonial protozoa and sulfur bacteria. In. INTERNATIONAL MICROIRRIGATION CONGRESS, 5, Orlando,1995. Proceedings. St. Joseph: ASAE, 1995. p.250-254.

SOLOMON, K. Manufacturing variation of trickle emitters. Transactions of the ASAE, St. Joseph, v.22, n.5, p.34-38, 1979. 